\title{
NOTES ON SOME DISTINCTIVE POINTS IN THE PUPAE OF WEST AFRICAN MOSQUITOS.
}

\author{
By A. Ingram, M.D., C.M., and J. W. Scott Macfie, M.A.,. D.Sc., \\ West African Medical Staff.
}

Wesché employed the relative length of the trumpets to the length of the thorax and the shape of the openings of the trumpets in drawing up a Key to the Pupae of West African Culicidae (Bull. Ent. Res., i, pp. 18-19). Howard, Dyar and Knab in their valuable monograph "The Mosquitoes of North and Central America and the West Indies" (Vol. i, pp. 102-103) state that in their experience too much has been made of the difference between the pupal trumpets of Anopheles and Culex; the variations in the shape, size, and length of the breathing trumpets between different species are numerous, they say, but " furnish no characteristics which are diagnostic of genera or larger groups." They consider that there are intermediate forms and that differences between species are frequently more striking than between genera themselves. They remark also that this may equally well apply to the differences in shape of the pupal paddles, admitting, however, that "there is a striking difference between the two tribes CuLICINI and SABETHINI" as regards the paddles for "In the Culicini the paddles are large, broad and rounded in outline; they are strengthened by a stout longitudinal midrib which bears a spine or seta apically. In the SABETHINI the paddles are much smaller, narrower and tapered to a point; the midrib is either absent or poorly developed and there is no spine or seta." It may be remarked here that in Eretmopodites, the only genus of the tribe SABETHINI up to the present known in Africa, the midrib is well developed in the pupal paddles and there is a long terminal seta, much longer than in the Culicins. Howard, Dyar and Knab believe that " the greatest diversity among the pupae of mosquitoes will be found in the number and arrangement of the setae on different parts of the body. These, we are sorry to say, have not been adequately studied, but we are convinced that they will furnish both generic and specific characters"; and they point out that "there is a well-marked difference in the two tribes above-mentioned. In the SABETHINI the seventh and eighth abdominal segments each bear a pair of ample fan-shaped tufts at the apical angles; these are absent in the Culicins."

Bacot takes up the question of the "possibilities of the pupal paddles (anal plates of Wesché) for purposes of classification and the separation of ill-defined species" of mosquitoes in his "Report of the Entomological Investigation undertaken for the Yellow Fever (West Africa) Commission " (pp. 140-146), stating that "very marked differences may occur in the pupal paddles of closely related species." Bacot qualifies this statement, however, by remarking that "there seems . . . no likelihood, so far as the scanty material examined goes, that these characters could be made to afford the basis for an independent scheme of classification." In the opinion of Bacot those appendages of the pupa which are obviously likely to be adaptive rather than ancestral in character may form a means of discrimination. 
Following Bacot we have described the pupal paddles of a few mosquitos which, so far as we know, have not yet been illustrated in this particular manner. It seemed to us, after reading Bacot's paper, that, while. helpful in the differentiation of certain species, a scheme of classification based solely upon the characters of the pupal paddles with their appendages would break down sooner or later. We must admit, however, that this break-down has not occurred so far as the examination of our materials has gone, yet the points of distinction are sometimes so slight that we believe that not only the numbers and arrangement of the setae on different parts of the pupal case should be taken into consideration, as suggested by Howard, Dyar and Knab, but also in certain cases the length and shape of the pupal trumpets, in attempting to draw up a scheme of classification based upon pupal characters alone. Such a provisional scheme we have outlined below for the pupae which have been figured by Wesché and Bacot, and for those we ourselves have had the good fortune to examine. Unfortunately we have not been able to avail ourselves of all the descriptions given by Wesché, as some of them are incomplete and his drawings, which were made at a low magnification, do not reveal certain minute points on which we have had to rely for the differentiation of species; this is especially the case in the genus Culex, in which we have had reluctantly to abandon the attempt to include his species in our scheme.

In drawing up this scheme we have relied as far as possible on the characters of the paddles and the setae on the last two abdominal segments. These structures furnished sufficient points for the differentiation of genera. In dealing with species, however, we have had to have resource to other characters in order to distinguish even the small number of pupae discussed, and it is probable that when further materials are available the setae on all or most of the abdominal segments and every other structure capable of giving assistance will have to be included in devising a complete scheme of classification.

\section{Table of Tribes.}

1. Paddles small, breadth less than half the diameter of the 8 th segment; tufts on the 8th segment as long as the paddles

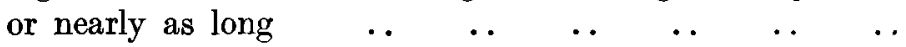

Paddles relatively large; tufts on the 8th segment shorter $\begin{array}{llllllll}\text { than the paddles } & \ldots & \ldots & \ldots & \ldots & \ldots & \ldots\end{array}$

2. Large species; long dorsal serrated hairs on the 7th and 8th $\begin{array}{lllllllll}\text { segments .. } & \ldots & \ldots & \ldots & \ldots & \ldots & \ldots & \ldots\end{array}$

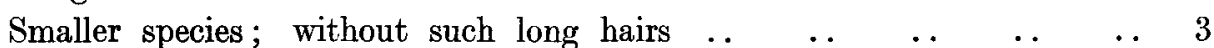

3. Dendritic seta on the posterior angle of the 8th segment .. Anophelini.

Tuft or differentiated seta on the posterior angle of the 8th

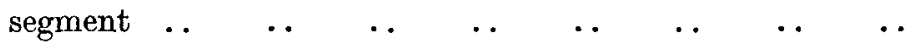

SABETHINI.

The only species belonging to the tribe MagarHININI the pupa of which has been described is Toxorhynchites brevipalpis, which has been figured by Bacot. The large size of the pupa is at present sufficient to differentiate it from any other, but the insignificant size of the tuft on the 8 th segment, the absence of terminal setae on the paddles, and the presence of long serrated dorsal setae on the $7 \mathrm{th}$ and 8 th segments are also characteristic. 
The pupae of Eretmopodites, the only genus of the tribe SABETHINI at present known to occur in Africa, differ from those of the SABETHINI described by Howard, Dyar and Knab, as has already been pointed out, in having well-developed midribs in the paddles, and long terminal setae or tufts of setae. The five species described, including one described by Bacot which is known only in the pupal stage, can readily be distinguished, as shown in the following table.

\section{Genus Eretmopodites, Theo.}

1. Single stout seta on the end of the paddle . $\quad \ldots \begin{array}{llllll} & \ldots & \ldots & \ldots & \ldots & 2\end{array}$ Tuft of about a dozen setae on the end of the paddle ..E. quinquevittatus. Tuft of about half a dozen setae on the end of the paddle .. $E$. inornatus.

2. A single stout seta on the posterior angle of the 8 th segment. . $E$. ? (undetermined).

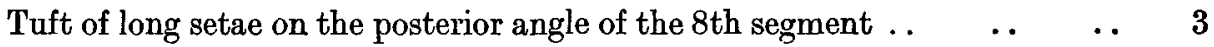

3. Tuft of four setae on the posterior angle of the 7th segment . . E. chrysogaster. Tuft of six setae on the posterior angle of the 7 th segment $\ldots \quad E$. dracaenae.

\section{Genus Anopheles, Mg.}

The pupae of only four West African species of this genus have hitherto been described in this way, namely those of $A$. costalis, $A$. pharoensis, and $A$. mauritianus by Wesché, and $A$. funestus figured by Bacot. The latter author also figured $A$. costalis. The pupa of $A$. marshalli is described here for the first time, and further details are given of those of $A$. pharoensis and $A$. mauritianus so as to make the descriptions of all the five species comparable.

\section{Anopheles marshalli, Theo.}

The pupal paddles are somewhat narrow, with a marginal fringe on the outer side. The thickening of the outer margin of the paddle or buttress, described by Wesché as present in the Anopheline pupae he examined, is also present in this species, but is less well developed than in $A$. costalis. There are two setae near the distal end of the midrib, the more distal one being the longer and stouter. The latter seta is not bent into a hook, as in the case of $A$. costalis and $A$. funestus in Bacot's figures, but is gently curved with the convexity inwards. The seta at the posterior angle of the 8th segment consists of branches coming off a main stem; the main stem is, however, much shorter than that of the lateral hairs of $A$. costalis. The 7 th segment carries no lateral tuft, but bears a single seta at its posterior angle, which is simple, and internal to it there is a longer but more slender seta, also simple. On the posterior border of the 5th and 6th segments there are similar setae, but the inner setae are usually double, and between them and the setae at the angles there are smaller double hairs, which, however, are larger than the similar hairs on the 7th segment. At the posterior angle of the 4th segment there is a small knob-like seta. On the posterior margins of the 2 nd, 3rd, and 4th segments there are several single, double and triple hairs, none of which however are strongly developed. 
Anopheles pharoensis, Theo. (fig. 1).

The paddles are pyriform, with a slight external fringe, and have well developed midribs; they have also an external buttress, which is less developed than in $A$. costalis. There are two terminal setae on each paddle, a large and a small one, as in the other species of this genus. The large hair is not bifid, though the small one, which is poorly developed, may be split at its end. These hairs lie further apart than do the similar hairs in $A$. mauritianus, and the larger hair is longer than the larger hair on the paddle of $A$. mauritianus (9 units to 7 ).

There is a stout irregularly branching dendritic seta, much like that of $A$. costalis, at the posterior angle of the 8th abdominal segment; it is about one-fifth the length of the paddle. At the posterior angles of the 5th, 6th, and 7th segments are stout, curved and sharply pointed setae, longer than the similar setae on the segments of $A$. mauritianus. At the posterior angles of the 3rd and 4th segments are curiously stunted and blunted setae. Internal to the seta at the posterior

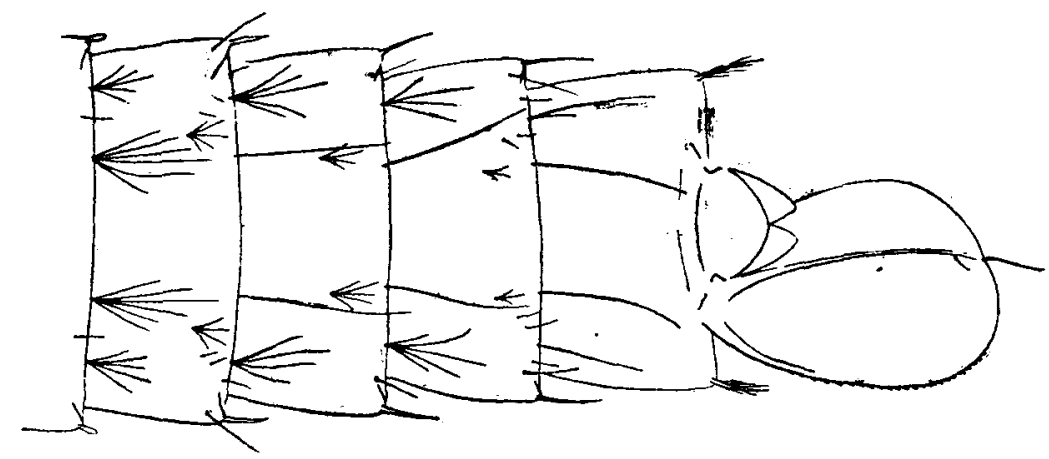

Fig. 1. Ancpheles pharoensis, Theo.*

angle and at the posterior border of the segments on the dorsum is a tuft of hairs upon the 3rd to the 6th segments; these hair-tufts have fewer hairs than the similar tufts on $A$. mauritianus; on the 7 th segment this hair-tuft is replaced by a single or bifid hair. Nearer the middle line of the dorsum on either side upon the posterior margins of the 5th, 6th, and 7 th segments is a single stout hair extending to the distal margin of the segment over which it projects; this hair is replaced by a tuft on the posterior border of the 3rd and 4th segments. The trumpets have wide apertures, which are not fluted.

Anopheles mauritianus, Grp. (fig. 2).

The paddles are large and pear-shaped, with a slight fringe on their outer margins; they have well-developed midribs and also buttresses, which are slighter than those of $A$. costalis. The terminal hairs on each paddle are a large hair, which is usually bifid, and a small one, which may have its end split into three or four pieces. The hairs are slightly curved, but not hooked.

At the posterior angle of the 8 th abdominal segment is a stout seta giving off delicate branches only upon its inner aspect; these branches all extend to about

* Lnless otherwise stated the magnification of all the drawing is $\times 50$. 
the same distance, namely to the termination of the seta itself, so that the branches coming off near the base are relatively long, while the others diminish in length progressively towards the apex-the appearance produced being suggestive of a harp.

There are short single stout setae with pointed ends at the posterior angles of all the segments proximal to the 8th, except the 1st. These setae gradually increase in size as the posterior end is approached. On the dorsal surface and at the posterior border of the segments immediately internal to the seta at the posterior angle there is a tuft of simple hairs on the 3rd to the 6th segments; on the 7 th segment this tuft is replaced by a single or double hair. On each side nearer the middle of the dorsum on the posterior border of the 6th and 7 th segments is a single or double stout hair extending slightly beyond the middle of the segment over which it projects; on the posterior border of the 3rd, 4th, and 5th segments this single hair is replaced by a tuft. The trumapets have wide apertures, which are fluted.

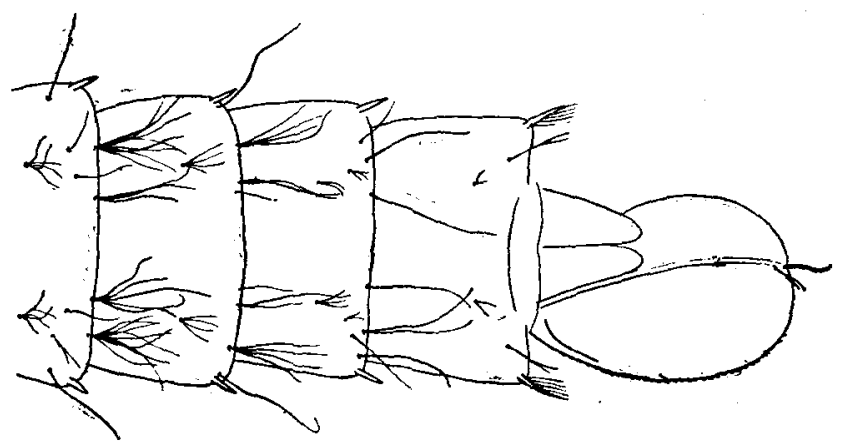

Fig. 2. Anopheles mauritianus, Grp.

With such a small amount of material it is scarcely worth while making out a table for identification, especially as there is no difficulty in separating the pupae, but a few of the many points of distinction may be briefly mentioned.

The buttress on the outer margin of the paddle is conspicuous in $A$. costalis, less well developed in $A$. pharoensis, and in A. mauritianus, as Wesché states, it is less well marked than in $A$. pharoensis. In $A$. marshalli it is only slightly developed. Unfortunately Bacot's figures do not show the buttress in either $A$. costalis or A. funestus.

The longer terminal seta on the paddle is "reminiscent of a boot-hook" in A. costalis and $A$. funestus, according to Bacot; in $A$. marshalli it is gently curved; in $A$. pharoensis it is almost straight, and in $A$. mauritianus it is usually bifid.

The dendritic setae on the posterior angles of the 8 th abdominal segment also differ in these species. In $A$. funestus they are "larger, with less spread of the branches" than in $A$. costalis, according to Bacot. In $A$. marshalli they are smaller than in $A$. costalis, their length as compared with the length of the paddle being as 7 to 35 in the former, and as 12 to 36 in the latter. In A. mauritianus they are harp-shaped. 
Tribe CULICINI.

Table of Genera.

1. Paddles of unusual shape.. $\quad$.

Paddles of usual shape, oval or pear-shaped ..

2. Paddles narrow, without fringe; end of trumpet meta-

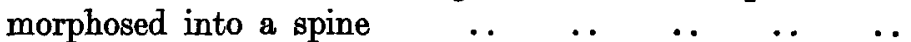

Paddles "knife-like," inner lobes larger than the outer $\quad . . \quad$ Uranotaenia.

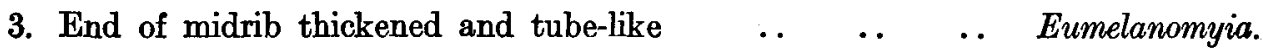

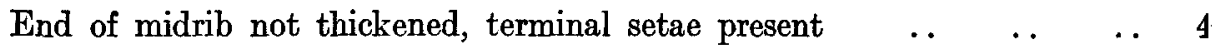

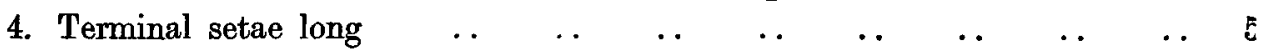

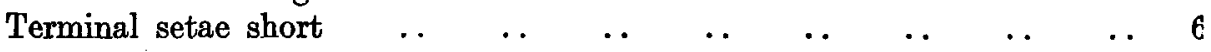

5. Terminal setae very long; stout dendritic seta with a very long central branch a little internal to the tuft on the 7th segment ..

Terminal setae shorter; no such dendritic seta on the 7th segment ..

6. Tuft on the 8 th segment small, no tuft on the 7 th ; paddles

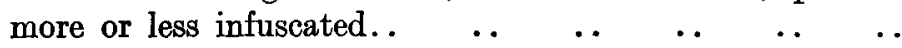

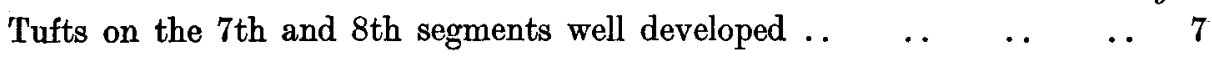

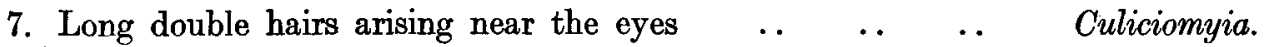
$\begin{array}{llllllllll}\text { No } \text { such hairs } & . & . & . & \text {. } & \text {.. } & \text {. } & \text {.. } & & \text { Culex. }\end{array}$

In the above table no attempt has been made to separate the genera Stegomyia and Ochlerotatus, but this will be referred to later when dealing with Aëdes.

Culiciomyia nebulosa possesses the two conspicuous hairs arising from a point near the eyes described by Wesché as present in the species he knew as C. freetownensis and C. cinerea, both of which have been sunk by Edwards. We do. not know if these hairs are present in other species of Culiciomyia, but as we have not observed them in any species of Culex it is possible they may prove to be a distinguishing feature.

\section{Genus Ä̈DEs, Mg.}

The only species of Ochlerotatus that we have had the opportunity of examining. differ from Stegomyia in having a small dendritic tuft on the 2nd segment similar to, but much smaller and more delicate than, that on the 1st segment. It may be possible therefore to differentiate these genera as follows:

Tuft on the 1st abdominal segment dendritic, almost no stem;

similar but smaller tuft on the 2 nd segment .. $\quad$.. $\quad$..

More decided stem to the dendritic tuft on the 1st segment; no

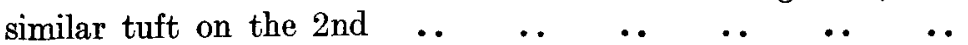

Ochlerotatus.

Genus Stegomyia, Theo.

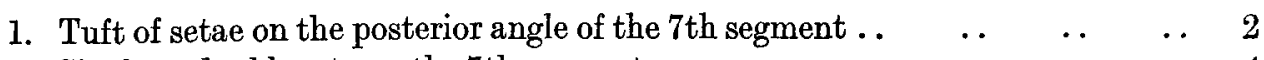
$\begin{array}{llllllll}\text { Single or double seta on the } 7 \text { th segment } & \ldots & \ldots & \ldots & \ldots & \ldots & 4\end{array}$

$\begin{array}{lllllllll}\text { 2. Paddles without a fringe } & . . & . . & \ldots & \ldots & \ldots & \ldots & & \text { S. sigens. }\end{array}$

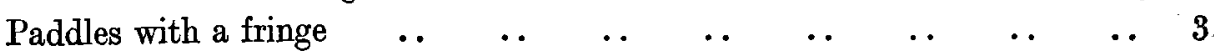


3. Stout branched seta at the posterior angle of the 6th segment,

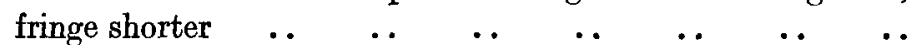

S. metallica.

No such special seta on the 6th segment; fringe longer; midrib

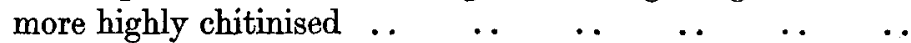

4. Paddles narrow ; single seta or a poorly developed tuft on the

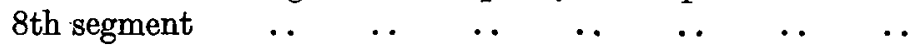

S. luteocephala.

Paddles broader; tuft on the 8 th segment well developed ..

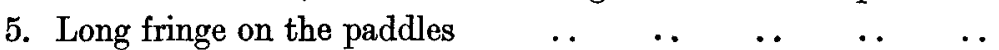

$\begin{array}{llllll}\text { Short fringe on the paddles } & \ldots & \ldots & \ldots & \ldots & \ldots\end{array}$

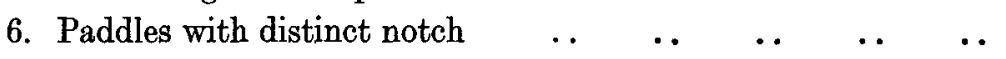

. $\quad \ldots \quad \quad \ldots \quad \quad \ldots \quad$ S. simpsoni.

7. Single seta on the 7th segment; tuft on the 8 th of subplumose

$\begin{array}{llllllllllllll}\text { hairs } & \ldots & \ldots & \ldots & \ldots & \ldots & \ldots & \ldots & \ldots\end{array}$

A single or usually a double seta on the 7th segment; tuft on

the 8 th with only one or two hairs subplumose .. ..

S. unilineata.

. $\quad .5$

S. africana.

. $\quad$. 6

. $\quad$. 7

S. apicoargentea.

S. fasciata.

The tufts and setae of Stegomyia are variable both in different individuals and on the two sides of the same pupa, so that it is necessary to examine more than a single specimen in those cases where these structures are used in differentiating the species.

We have not had an opportunity of examining the pupae of $S$. sugens, S. africana, and $S$. apicoargentea but have relied on the descriptions by Wesché for the differential points.

\section{Stegomyia Iuteocephala, Newst.}

The paddles are oval and rather narrow, but not so narrow as those of $S$. unilineata, they have a long fringe and a highly chitinised midrib, and the terminal seta is well developed. There are tufts at the posterior angles of the 7 th and 8th segments, those of the 8th segment being the larger. These tufts vary in size considerably, and those on the 7 th segment may be reduced to stout bifid hairs in some specimens, but as a rule they are well developed on one or other side of the body. On the 8th segment there is a single simple hair internal to the tuft, but the segment is otherwise almost bare. All the other segments carry a number of small setae, especially at their posterior margins, which are mostly simple, although a few are bifid; none of these hairs is conspicuously or strongly developed. The dendritic tufts on the first segment are not very strongly developed and have only a small number (about 7 ) of primary branches.

\section{Stegomyia metallica, Edw. (fig. 3).}

The paddles are oval, with a short fringe, a well-developed midrib, and a long terminal seta. At the posterior angles of the 7 th and 8 th segments there are setae differentiated as tufts of subplumose hairs; those on the 8th segment being small but definite tufts, those on the 7 th being little more than strong double or triple branched hairs. The 8th segment is bare but for the tuft at each angle and a small simple hair internal to it. On the 7th segment there are, in addition to the tufts, a number of simple hairs, mostly situated on the posterior margin, and a pair of 
triple hairs. The 6th segment has at each posterior angle a strong bifid seta, on its posterior margin a number of simple and one pair of bifid setae, and a few small hairs further forward. The 5th segment has a single stout hair at the posterior angle and a number of small hairs near the posterior margin, one of which is larger than the others. The setae on the 4th segment are similar to those on the 5th, but the long hair is more highly developed. On the posterior margin of the 3rd segment, in addition to small hairs, there are on each side of the mid line a double or triple

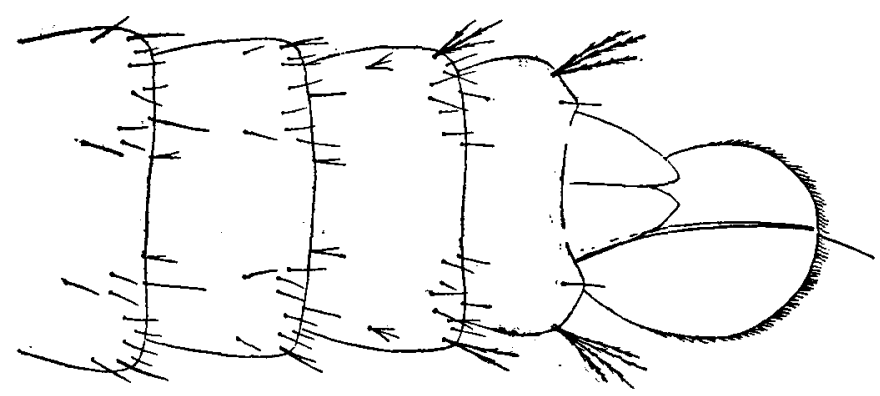

Fig. 3. Stegomia metallica, Edw.

and a long simple seta. On the 2 nd segment these setae are more highly developed and the inner one is composed of four bra nches. All these setae on the 2nd to the 8th segments are more highly chitinised and better developed than those of $S$. luteocephala. The dendritic setae on the lst segment are well developed and have about a dozen primary divisions.

\section{Stegomyia simpsoni, Theo.}

The paddles are broader than those of the two species just described and show a distinct notch at the point where the midrib ends; they have a slight fringe; the midrib is well-developed, and they carry the usual long terminal seta. On the 8th segment there is a small tuft at the posterior angle, some of the hairs of which are subplumose, and a single or bifid seta internal to it. The 7th segment bears a few quite small setae, mostly at its posterior margin, and at the posterior angle two larger setae, one of which is larger and stronger and is situated a little anterior to the other. The 6th segment shows similar hairs and one strong seta a little above the posterior angle. On the 5th segment the small hairs are mostly bifid and sometimes triple, the strong seta above the posterior angle is present, and in addition there is a long, strong seta on the posterior margin a little internal to the angle. The 4th segment bears similar hairs, but the strong seta above the posterior angle is smaller, and the long seta internal to the angle is more highly developed. On the 3rd segment the seta above the posterior angle is reduced still more, and on the posterior margin internal to the angle there is a small tuft and then a seta of moderate size. On the 2nd segment there are a few simple and divided hairs, none of which is specially developed. The dendritic hairs on the 1st segment are well-developed and show more than a dozen (about 16) primary divisions. 
Stegomyia unilineata, Theo. (fig. 4).

The paddles are narrower than is usual in the other members of this genus, the ratio of length to breadth being on the average as 1.6 is to 1 ; they have a stout midrib, a well developed fringe, and a long terminal seta. The abdominal setae are very variable in this species both in different individuals and on the two sides of the same specimen. The 8 th segment is almost bare but carries at each posterior angle a stout seta, and internal to it a small hair. The seta at the posterior angle is well developed and may be single, double, or composed of three or four elements : it is subplumose. At the posterior angles of the 6th and 7th segments there are similar stout setae, but anterior to this there is little or no differentiation of the setae in this position. The seta at the posterior angle of the 7 th segment is pubescent and may be single or double, that on the 6th segment is much smaller, simple, and either single or bifid. All the segments from the 2nd to the 7 th bear numerous setae, the majority of which are situated on the posterior margins. Most of these

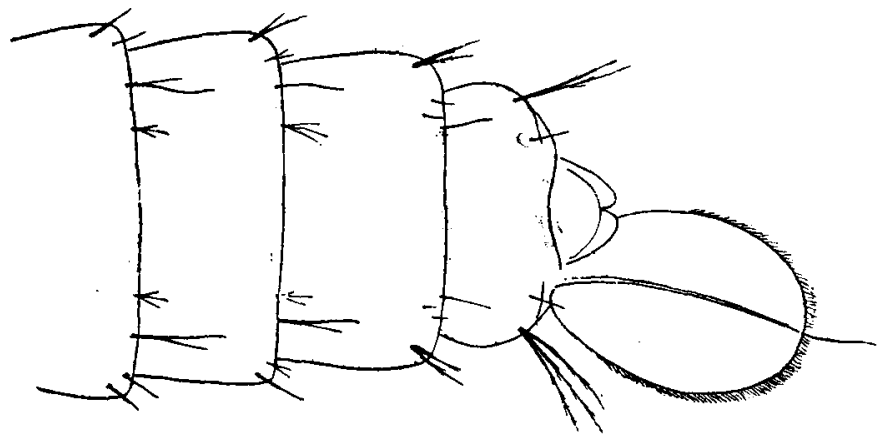

Fig. 4. Stegomyia unilineata, Theo.

setae are small, but two series are rather more highly developed. The one series is situated on the posterior margins about half-way between the mid line and the posterior angles and is represented by a long, single seta on the 6th and 7th segments, a long single or double seta on the 4th and 5th segments, and a long single seta on the 2nd and 3rd segments. The second series lies slightly internal to the first, and the setae composing it are developed into tufts, which gradually become smaller as the posterior extremity is approached. On the 2nd segment the tufts are usually well developed, on the 3rd and 4th they are smaller and consist of only four or five hairs, on the 5th and 6th they are reduced to triple hairs, and on the 7th they are represented by single or double hairs not specially differentiated from the other small setae on the segment. The dendritic setae on the 1st segment are well developed and have a large number (over a dozen) of primary divisions.

The above description is based on the examination of five pelts of pupae of this species.

Genus Ochlerotatus, Arrib.

1. Two small dark spots on the margin of each paddle $\quad . \quad \ldots \quad$ O. sudanensis,

No such spots 
2. Single seta at the posterior angle of the 8th segment .. $\quad \ldots \quad$ o. domesticus.

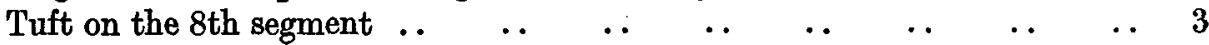

3. Tuft on the 8 th segment long, half the length of the paddle or more .. $\quad$. 4 Tuft on the 8th segment short, less than half the length of the paddle $\quad$. 5

4. Paddles with a fringe and a single long terminal seta .. . . O. apicoannulatus.

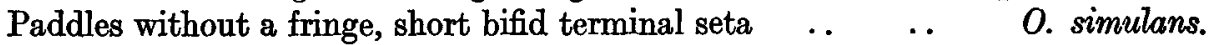

5. (Paddle plates " run at sharper curve from the ribs") $\quad$. O. nigricephalus.

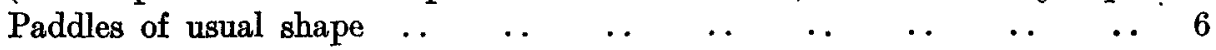

6. Paddles with a fringe $\quad \ldots \quad$. $\begin{array}{llllllll}\text { Paddles without a fringe } & \ldots & \ldots & \ldots & \ldots & \ldots & \ldots & \text { O. minutus, }\end{array}$

O. punctothoracis, O. caliginosus.

This table is given with considerable diffidence, as we have ourselves examined only two of the species. Bacot figures three, namely, $O$. simulans, O. apicoannulatus and $O$. minutus, $O$. sudanensis was briefly mentioned by us in a previous paper (Bull. Ent. Res. vii, p. 7), and the others were described by Wesché. O. albocephalus, Theo., has not previously been described, or figured.

Ochlerotatus albocephalus, Theo (fig. 5).

The paddles are oval in shape and show a well marked midrib, a slight external thickening or buttress, a slight but distinct external fringe, and a long terminal seta. The terminal seta is one-fifth the length of the midrib and in this respect resembles that of 0 . minutus as figured by Bacot. The 8 th segment bears at each posterior

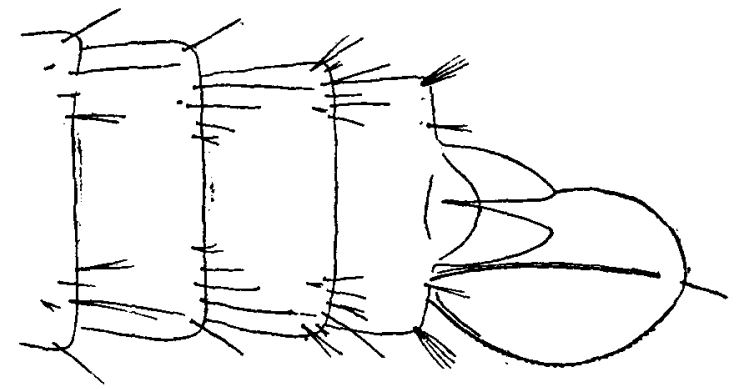

Fig. 5. Ochlerotatus albocephalus, Theo.

angle a small tuft of about four simple or pubescent hairs, which is just about the same length as the terminal seta on the paddle, namely, one-fifth the length of the midrib. Internal to the tuft, close to the outer margin of the paddle there is a long, slender, single or bifid hair. At the posterior angle of the 7 th segment there is a bifid seta and a few small hairs, and along the posterior margin of the segment are a number of delicate and rather long hairs. On the 4th, 5th and 6th segments one of the setae on the posterior margin and a little internal to the angle is especially developed, so that it reaches right across the following segment. This seta may be single or double. The dendritic setae on the 1st segment are well developed. On the 2nd segment there is also a pair of dendritic setae, which are, however, much smaller than those on the lst segment and but poorly chitinised. 
Genus Mansonioides, Theo.

The early stages of Mansonioides uniformis are not known. The pupa of $M$. africanus can readily be distinguished from all other known West African pupae by the structure of the trumpet, which is developed at its distal end into a spine suitable for piercing the roots of the water-weed Pistia stratiotes, but it can also be separated from pupae of other genera of the tribe CuLICINI by the characters of the paddles alone.

The structure of the paddles has been figured by Ingram (Bull. Ent. Res. iii, p. 377) and it is only necessary here to add that the ends are slightly thickened and that apparently there are no terminal setae. At the posterior angles of the 7 th and 8th segments there are large single setae in place of tufts.

Genus Ä̈Domyıa, Theo.

Aëdomyia africana, N.L. (fig. 6).

The paddles are pyriform, slightly notched, and without a fringe ; the outer margin is a little thickened and the midrib is well developed. There is a single stout terminal seta at the end of the paddle about as long as the paddle itself. In the middle line and at the distal end there is a slightly darkened patch.

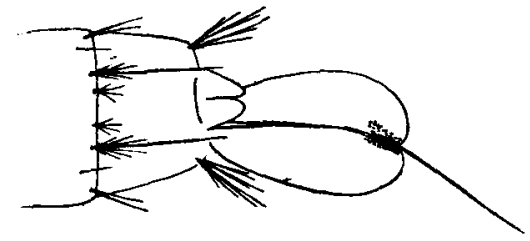

Fig. 6. Aëdomyia africana, N.L.

The tufts at the posterior angles of the 8th segments are well developed and consist of four branched hairs. On the 7th segment there is a stout double seta at the posterior angle, and internal to it another tuft formed by the branching of a stout seta the median element of which is extremely long. Similar long tufts, or more correctly dendritic setae, are also present on the 4th to the 6th abdominal segments. Internal to these, and in a similar position on the 1st, 2nd and 3rd segments also, there is a tuft of slender hairs. The dorsal tuft on the lst abdominal segment is poorly developed.

There are several tufts on the thorax, one of which lies just behind the trumpets and another at the posterior margin. The trumpets are not very long, but are highly chitinised.

\section{Genus Culex, L.}

1. Tuft at the posterior angle of the 8 th segment containing

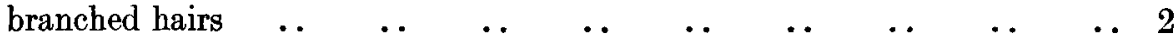

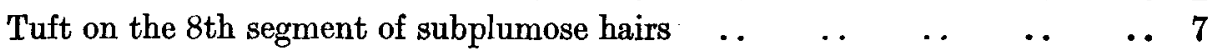

2. Tuft at the posterior angle of the 7th segment containing $\begin{array}{lllllllllll}\text { branched hairs } & \ldots & \ldots & \ldots & \ldots & \ldots & \ldots & \ldots & \ldots & \ldots & 3\end{array}$

Tuft on the 7th segment of subplumose or simple hairs $\quad \ldots \quad \ldots \quad \ldots \quad \ldots \quad 5$ (C365) 


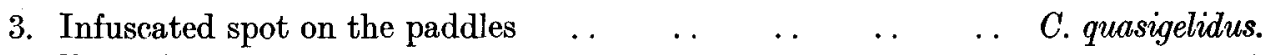

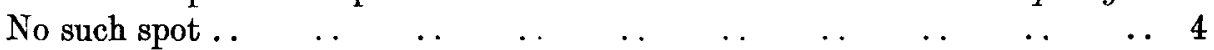

4. A triple hair at the posterior angle of the 5th and 6th

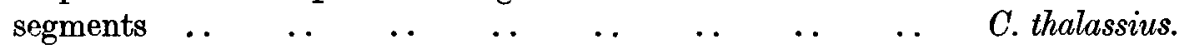

A tuft of five or six hairs at the posterior angle of the 5th $\begin{array}{lllllll}\text { and } 6 \text { th segments .. } & \text {.. } & \text {.. } & \text {.. } & \text {.. } & \text {.. } & \text { C. tritaeniorhynchus. }\end{array}$

5. Large species; length of the paddle about $0.9 \mathrm{~mm}$. $(70$

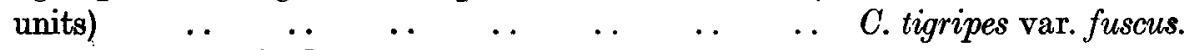
$\begin{array}{lllllllll}\text { Small or medium-sized species } & \ldots & \ldots & \ldots & \ldots & \ldots & \ldots & \ldots & 6\end{array}$

6. Stout pupa, well chitinised; tubal aperture large (19 $\begin{array}{llllll}\text { units to a trumpet length of } 42 \text { units) } & \text {. } & \text {. } & \text {.. } & \text {.. } & \text { C. fatigans. }\end{array}$

Slender pupa, poorly chitinised; tubal aperture smaller (10 units to a trumpet length of 35 units) $\quad . \quad$.

7. Tuft on the 8th segment long, more than half the length of the paddle (19 to 34 ); trumpets short ..

Tuft on the 8th segment shorter, less than half the length of the paddle $(8: 42)$; a pair of long hairs on the distal margin of the 6th segment ; trumpets larger $\ldots \quad \ldots \quad$ C. guiarti.

In drawing up this table it has been necessary to take into account certain minute characters which unfortunately has made it impossible to include some of the species described and figured by Wesché in insufficient detail. It has also been necessary to re-describe $C$. fatigans and $C$. invidiosus in order to bring out these points. The branched or subplumose character of the hairs composing the tufts at the posterior angles of the 7th and 8th segments is not a very satisfactory differential feature and has been adopted in the table only because it was emplayed by Wesché. Four of the species have not previously been described.

It may be noted as a point of possibly generic importance that none of the species of $C u l e x$ that we have examined has had a fringe on the pupal paddles.

Culex fatigans, Wied. (fig. 7).

The pupa is stout and well chitinised. The paddles are large and slightly pyriform, with a well developed midrib and a slight thickening of the external border, but without a fringe. At the distal end of the midrib there are two small setae situated close together, the one being rather longer than the other. At the posterior angle of the 8 th segment there is a tuft of about 6 to 8 branched hairs. At the posterior angle of the 7th segment there is a group of three setae; the one nearest the angle is a small tuft of 4 or 5 delicate hairs, just above it is a larger tuft of 3 to 5 stout hairs, which are usually subplumose but may be branched, and internal to this seta and a little above it is a small double or triple hair. Several other hairs are situated along the posterior margin of this segment, most of which are small and double, but one particularly long single hair may be found near the angle. The 6th segment bears just above its posterior angle a long delicate triple hair, on the posterior margin a little internal to the angle a very long double hair, and just internal to this a tuft of 4 hairs. Similar setae occur on the 5th segment, but the tuft internal to the angle is composed of rather more hairs, 5 usually. On the 4 th segment the long lateral seta is sometimes double, 
sometimes quadruple and the tuft internal to it comprises 5 to 7 hairs. On the 3rd segment there is a tuft of 7 or more hairs on the posterior margin a little internal to the angle. There are only a few small setae at the posterior angle of the 2nd, 3rd,

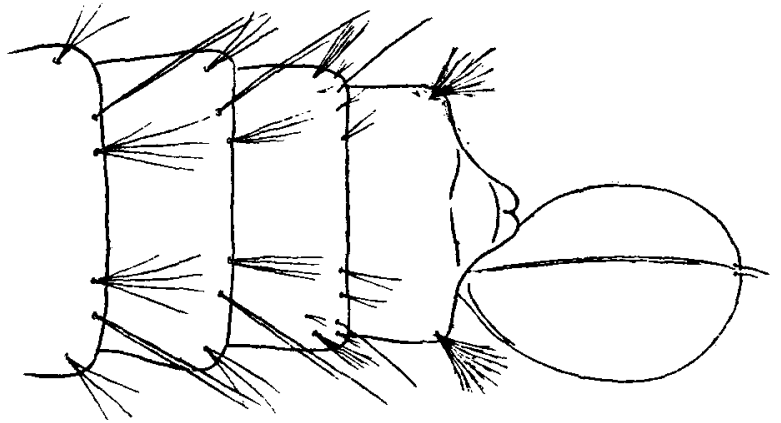

Fig. 7. Culex fatigans, Wied.

and 4 th segments. The dendritic setae on the 1st segment are well developed, there is also a pair of small dendritic setae on the 2 nd segment. The pupal trumpets are relatively short, but have a large aperture.

Gulex invidiosus, Theo. (fig. 8).

The paddles are similar to those of $C$. fatigans, that is, they are pyriform and have a well developed midrib, a slight external thickening, but no fringe. At the free end of each midrib are two small setae, set close together, one of which is a little larger than the other. The pupa is, however, much more delicate than that of $C$. fatigans and

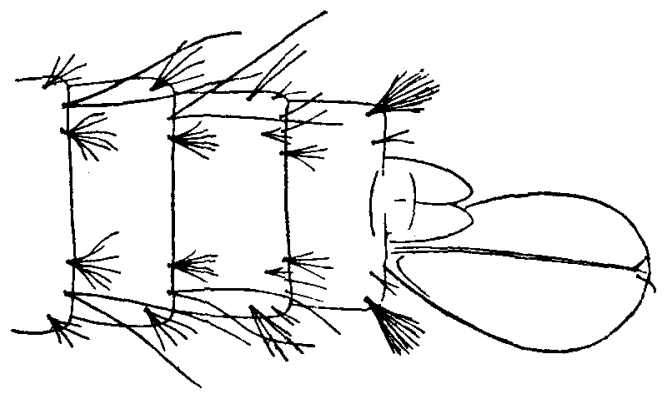

Fig. 8. Culex invidiosus, Theo.

is but poorly chitinised. The 8th segment bears a tuft at its posterior angle, and a delicate double hair close to the insertion of the paddle. The tuft is composed of 7 to 9 branched hairs. There are several delicate setae near the posterior angle of the 7 th segment the most conspicuous of which is a tuft composed of 2 to 4 hairs, which may be either simple or subplumose. This tuft lies a little above the angle and close to the lateral margin of the abdomen. On the posterior margin of this segment and about half way between the angle and the mid line, there is a delicate tuft of about 4 hairs. The 6th segment has a delicate tuft of about 5 hairs in the posterior angle, an extremely long double seta on the posterior margin a little internal to the angle, 
and internal to this a tuft of about 7 delicate hairs. The 5th segment bears similar setae to those on the 6th segment. On the posterior margin of the 4th segment there are two tufts a little internal to the angle, the outer composed of about 6 hairs and the inner of about 10. On the 3rd segment there are two similar tufts, the outer one of which is however much reduced. On the 2 nd segment there are two delicate dendritic setae with long peduncles. The dendritic setae on the 1st segment are well developed.

The pupal trumpets have a smaller aperture than those of $C$. fatigans.

Culex thalassius, Theo. (fig. 9).

The paddles are broad, with a well marked midrib, and an external thickening, but without a fringe. There are two small terminal setae, the larger of which is sometimes bifid. On the 8th segment there is a large tuft of 10 to 12 branched hairs at the posterior angle, and a small double hair near the external root of the paddle. On the 7 th segment there is a small tuft of about 7 delicate hairs close to the posterior angle,

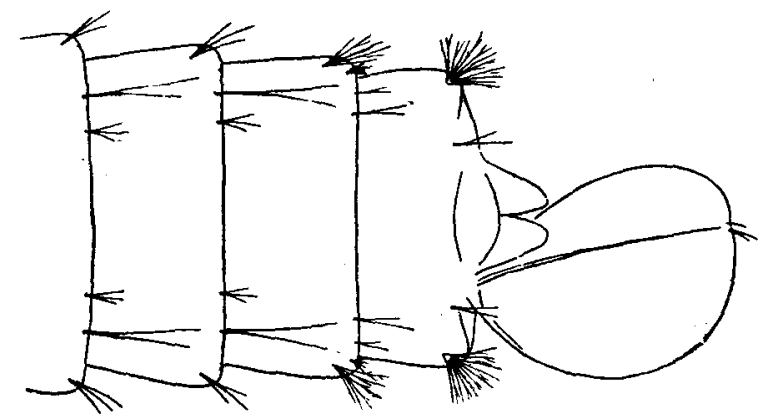

Fig. 9. Culex thalassius, Theo.

and a little above this a larger tuft of 4 to 6 stout branched setae. On the 6 th segment there is at the posterior angle a delicate triple or double hair, but the most conspicuous seta lies a little internal to this on the posterior margin, and is long, strong, bifid, and pubescent or subplumose. The setae on the 5th segment are similar to those on the 6th. On the 4th segment the seta at the posterior angle is sub-divided into a tuft of about 5 delicate hairs, and the conspicuous seta internal to it is sometimes triple. On the 3rd segment the tuft near the posterior angle consists of about 6 elements, but the stout seta internal to it is no longer conspicuous. On the 2nd segment there is a small dendritic seta. The dendritic seta on the lst segment is large and shows about 8 primary divisions.

Culex tritaeniorhynchus, Giles. (fig. 10).

The pupal paddles are similar to those of $C$. thalassius; they are without a marginal fringe, and their terminal setae are paired but very small. The more conspicuous abdominal setae are as follows. On the 8th segment there is a lateral tuft of about 6 branched hairs. On the 7th segment there is a minute tuft in the posterior angle and just above it a larger tuft of 4 branched setae, and on the posterior margin about half-way between the angle and the mid line there is a tuft of 4 hairs. On the 4th, 
5 th, and 6th segments there is at the posterior angle a tuft of 5 or 6 hairs; just internal to this a stout double seta, which is not so well developed as in C. thalassius; and again internal to this and on the posterior margin a tuft of 6 to 8 hairs. The latter tuft is larger on the 4th and 5th segments than it is on the 6th, but on the 3rd segment

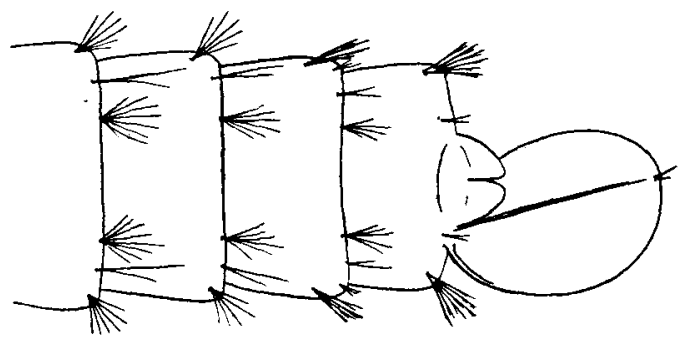

Fig. 10. Culex tritaeniorhynchus, Giles.

there is a similar tuft which is rather larger than that on the 4th segment. On the 2nd segment there is a small dendritic tuft. The dendritic tufts on the 1st segment are well developed and have about a dozen primary branches.

Culex guiarti, Blanch. (fig. 11).

The pupa as a whole is very poorly chitinised. The paddles show no marginal fringe; they have paired small and slender terminal setae. Most of the abdominal setae are poorly chitinised, the only conspicuous ones being the lateral tufts on the 7 th and 8 th segments, and the very long double setae on the 5 th and 6 th segments. Near the posterior angle of the 8th segment there is a tuft of 7 or 8 subplumose hairs ; this tuft is small, being less than a quarter the length of the midrib. In a similar

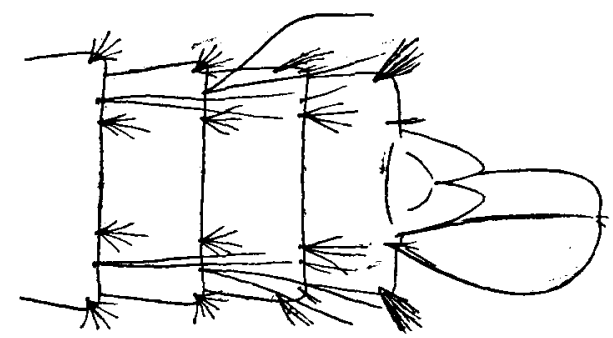

Fig. 11. Culex guirti, Blanch.

position on the 7th segment there is a tuft of 3 or 4 subplumose hairs, and on the more anterior segments delicate tufts of about 5 fine hairs. On the posterior margin a little internal to the angle there is on the 5th and 6th segments a strong double or triple seta of great length; in a similar position on the 4th segment there is a tuft of 5 hairs. A little internal to these setae there are delicate tufts on the 3rd to the 7 th segments. The dendritic setae on the Ist segment are large and much branched. The trumpets are long, poorly chitinised, and have a narrow aperture. 
Genus Cyathomyia, Theo.

Cyathomyia fusca, Theo. (fig. 12).

The paddles are rather small, with a slight external thickening, a midrib, but no fringe ; they carry paired terminal setae, which are small and very delicate. On the 7 th and 8th segments there are conspicuous lateral tufts ; those on the 8th segment are long and are composed of 7 subplumose hairs, those on the 7th of 4 or 5 hairs, subplumose towards their extremities and branched at their tips. No such tufts

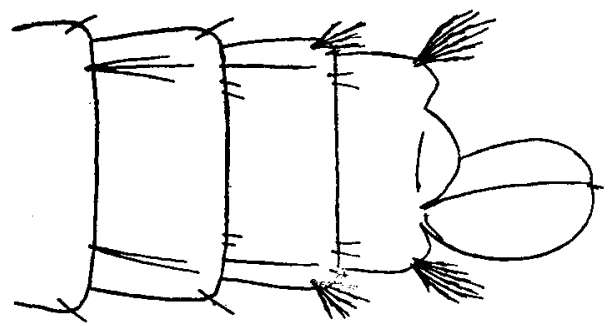

Fig. 12. Cyathomyia fusca, Theo.

are present on the other segments, which carry at their posterior angles only a few minute setae. On the posterior margins of the 4 th, 5 th and 6 th segments there is a specially large seta a little less than half-way between the angle and the mid-line; this seta is single on the 6th segment and double or triple on the 4 th and 5th. The trumpets are short, highly chitinised and with a moderately wide aperture.

Genus Eumelanomyia, Theo.

Eumelanomyia inconspicuosa, Theo. (fig. 13).

The pupa of this mosquito possesses pear-shaped paddles with a distinct external buttress; the midrib is well formed and has a peculiar expansion at its end; no terminal seta was visible in the single specimen examined. At the posterior angle of the 8th abdominal segment there is a fan-shaped tuft of 8 subplumose hairs; near

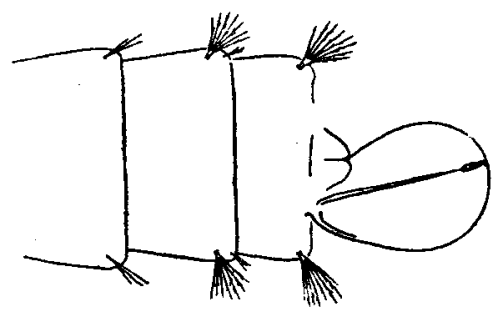

Fig. 13. Eumelanomyia inconspicuosa, Theo.

the posterior angle of the 7 th segment there is a fan-shaped tuft of 7 less well developed subplumose hairs, but actually nearer the posterior angle there is a slender triple hair; near the posterior angle of the 6th segment there is a slender triple hair. The trumpets are rather long and narrow, slightly expanded at the ends and with small apertures. The whole pupa is dark and strongly chitinised. 
Genus Mrmomyia, Theo.

Edwards in his " Revised Keys to the Known Larvae of African Culicinae" has given a table by means of which the pupae of $M$. splendens, $M$. plumosa, $M$. mimomyiaformis, and $M$. hispida can be distinguished. In the following notes we give certain additional points of importance with regard to two of these species.

\section{Mimomyia mimomyiaformis, Newst (fig. 14).}

The pupa as a whole is dark, and the paddles and the middle parts of the abdominal segments are covered by minute spines. The paddles are pyriform, the inner distal angle, however, is characteristically squared; they are infuscated with a white

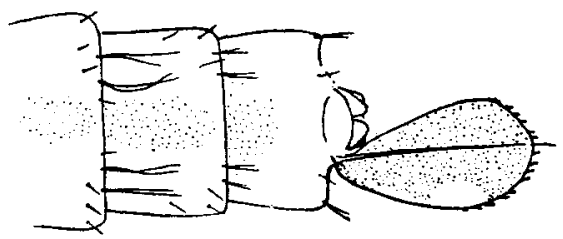

Fig. 14. Mimomyia mimomyiafırmis, Newst.

comma-shaped marking on their outer sides; there is a fringe of large sparsely scattered points; the midrib is well developed, and there are single short terminal setae. The tufts at the posterior angles of the 8 th segment are very small and consist of only 2 or 3 short hairs. On the 7 th segment there are only a few minute setae near the posterior angle, and on the posterior margin a little internal to these two rather larger bifid setae. The latter setae are better developed on the anterior segments, and are further subdivided. The dendritic setae on the lst segment are poorly developed and but little branched. The trumpets are long and pale at the tips.

Mimomyia splendens, Theo. (fig. 15).

The paddles are narrow, ending in a small knob-like projection, and slightly darkened at the tips. There is a well developed buttress both on the inner and outer margins of the paddles, but the midrib is poorly developed distally. The fringe on the paddles is long. The terminal setae are small, and there is a small seta close to

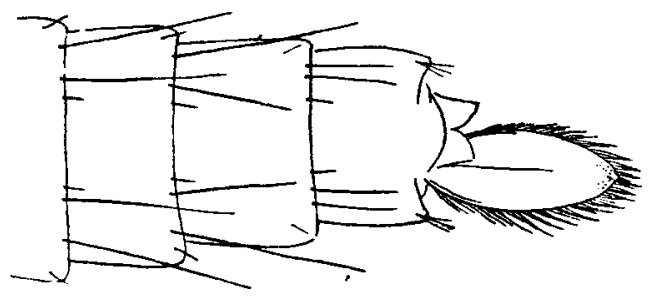

Fig. 15. Mimomyia splendens, Theo.

the midrib a little distance from the end. The tuft at the posterior angle of the 8 th segment is poorly developed and consists of only one or two short hairs ; the posterior angle itself is almost tooth-shaped. At the posterior angle of the 7th segment 
there are only a few minute hairs. On the 2 nd to 7 th segments there are on each side two long powerful setae on the posterior margin a little internal to the angle, and a small stout seta internal to them; these setae are more highly developed on the anterior segments, and on the 7 th segment may be poorly represented. The dendritic setae on the 1st segment are small and sparsely branched. The trumpets are long and pale for the apical third, but the actual end is somewhat darkened.

\section{Genus Uranotaenta, Arrib.}

The only species of this genus that we have examined is $U$. balfouri. The paddles are peculiar in shape, as described by Wesché, that is the plates on the inner sides of the midribs are larger than those on the outer sides, an arrangement we have not observed in any other pupae.

The paddles of $U$. balfouri appear to be more pointed at the apex than those of $U$. ornata, which has been figured by Bacot, and the pupa differs also in having a fanshaped tuft of simple hairs near to, but not actually at the posterior angle of the 7 th abdominal segment, and the small tufts at the posterior angles of the 8th segment composed of only two hairs. In the specimen of $U$. balfouri examined by us there was also a dark ring at the base of the paddles.

\section{Sub-family CHAOBORINAE.}

\section{Genus Chaoborus, Lichtenstein.}

Chaoborus ceratopogones, Theo. (figs. 16, 17).

The pupa is less curved than the pupae of the CoLicLnaE. It has very large paddles of a peculiar shape ; these paddles have a well developed buttress on their inner side and their internal margins are fringed, the midrib is broad and lies nearer the inner

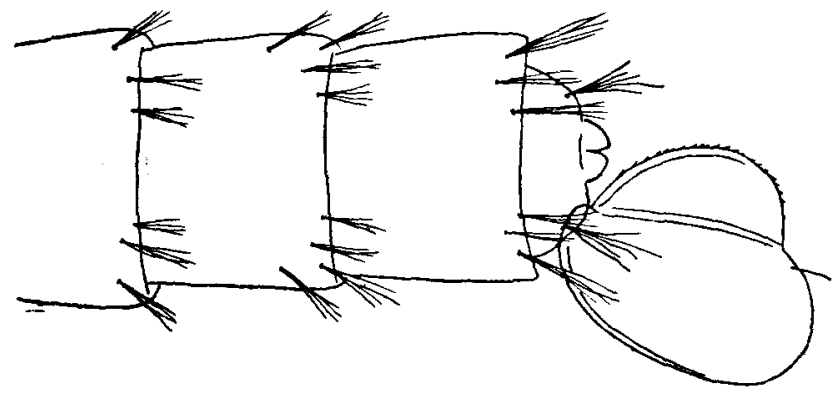

Fig 16. Chaoborus ceratopogones, Theo.

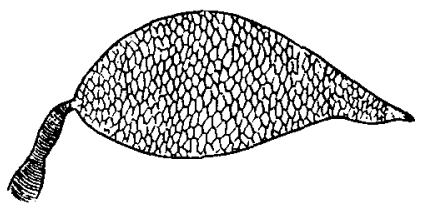

Fig. 17. Pupal trumpet of Chaoborus ceratopogones, $\times 75$.

than the outer side of the paddle, the inner lobe being thus narrower than the outer. There is a single slender terminal hair at, some distance to the outer side of the end of the midrib. The pupa seems to be devoid of stout hairs, but there are delicate tufts near the posterior angles of all the segments and along the posterior margins. These tufts might easily be overlooked. The trumpets bear but a slight resemblance to the trumpets of the CULICINAE ; they are flask-shaped or pear-shaped, with the narrow end outwardly directed; their surface is beautifully reticulated, suggesting an 
alveolar-structured organ possibly functioning as a primitive lung; the trumpets have an exceedingly narrow slit-like opening distally and the proximal ends are connected with well marked tracheae, which narrow at their junction with the trumpets and become broader and more convoluted as they are traced into the interior of the pupal case. Miall (Aquatic Insects, p. 119) states that "The pupa floats in an upright position at the surface of the water." This statement is incorrect so far as the pupa of Chaoborus ceratopogones is concerned, as it appeared to spend the whole of its time at the bottom of the water in the glass vessel wherein it was placed.

The pupal stage lasted about 36 hours in the two specimens bred.

In conclusion, we desire to express our thanks to Dr. Guy A. K. Marshall, Director of the Imperial Bureau of Entomology, for his kind assistance in determining several of the species here dealt with; and to Miss Rhodes for the great care and trouble she has taken in the preparation of the illustrations. 